\title{
School Community Participation and School Health Promotion: Challenges and Opportunities
}

\author{
Dr. Siphokazi Kwatubana
}

NWU (Vaal Campus)
Email: sipho.kwatubana@nwu.ac.za

\section{Doi:10.5901/mjss.2014.v5n27p1458}

\begin{abstract}
Issues surrounding community participation at schools are frequently debated in South African education spheres. However, communities remain not totally convinced to participate in health promoting activities at schools. In this paper I report on the importance of community participation in health promotion processes at schools and elaborate on what community participation entails, its levels and reasons for non-participation. Data was generated from two strata: principals and chairpersons of health committees by means of semi-structured one-to-one interviews. The findings revealed that participating schools had an opportunity to build strong links with community organisations to sustain their School Health Promotion initiatives but failed due to lack of trust and leadership. The challenge in these schools is lack of understanding of community participation and its benefits.
\end{abstract}

Keywords: organisational change, change theories, full participation, levels of participation, triggers for change, non-participation

\section{Introduction}

A prerequisite for holistic development and effective learning in children is a healthy learning environment. A healthy learning environment contributes to a child's health, emotional wellbeing and academic performance, it is thus important for schools to engage school communities to fortify their efforts of health promotion. Orthodoxly, the school community has always been awarded a place in the school hierarchy that of participating in school governance. Community members in the school governing body (SGB) are expected to execute policies and contribute their ideas and opinions to enhance school effectiveness. Some school community members are involved in community health projects in their communities this could mean that they are conversant with health policies. It would therefore be unwise to ignore vast experiences of community members central to successful health promotion initiatives at schools. Community participation is therefore a critical element of health promoting schools where partaking in shared decision-making, responsibilities and outcomes is the norm.

Health education has always been part of the school curriculum in South Africa, however, the global trends, the Ottawa Charter and the Education For All (EFA) push for a change in the health promotion approach. Responding to these changes South Africa modified its school health policies from 2010, policies that intended to address a single health problem were integrated to target multiple health problems simultaneously (see ISHP, 2012; South Africa, 2010). The introduction of these alterations comes at a time when educators are still grappling with the new Curriculum Assessment Policy Statement (CAPS) (Department of Basic Education, 2012). A myriad of changes often create stress and can exacerbate the neglect of important interventions intended to create a conducive, healthy environment for general school effectiveness. Schools are thus, continuously in need of support on handling difficult tasks to enable them to improve their performance.

A whole school model of health promotion as recommended by the World Health Organisation (1997) focuses on the development and implementation of health policies and programmes by educators, learners and community members as coequals. This research argues that full, meaningful community participation completes any model of health promotion implemented in any schools. The Inter-Agency Network for Education in Emergencies (INEE) (2004 p. 80) defines community participation as referring to both the processes and activities that allow members of a particular population to be heard, empowering them to be part of decision-making processes and enabling them to take action in conjunction with other structures on health promotion issues. Shared decision making contrasts with traditional methods of relying entirely only on schools to take decisions and effect health policies. Adoption of a participative approach will enable communities to share their expertise and resources in support of their schools. Such support can only be realized if old assumptions 
about communities are modified to allow a norm of equality and shared power with school communities as integrated team players.

Research conducted on the effectiveness of health promotion in schools highlighted lack of involvement of communities in the implementation of health programmes as a barrier to success. Because of lack of understanding of the concept of health promotion, schools embark on the use of trial and error strategies which often lead to more confusion, conflict and stress. Research has shown that schools that involve communities in their health promotion efforts report fewer problems in implementation and execution of health processes. There is a lack of documented evidence regarding challenges and opportunities in community participation in health promotion in schools.

\section{Theoretical Framework}

The health promotion theory guiding this research is that of organisational change. As there are multiple views of organisational reality Senge's model of learning organisations (1990) is regarded suitable for this research. Senge combines four theories in his approach to change. Regarding the first theory, evolutionary Sporn (1999), argue that because organisations are not self-sustaining they are forced to make a choice to adapt to their environment in order to survive. Organisational settings that present preparedness or are able to identify a need to change, are key to effective implementation of health programmes. In this second theory, teleological, collaborations, staff development, effective leadership and change agents are the greatest contributors to transformation and change (Kezar, 2001). The blending of the evolutionary and teleological theories makes it possible for change to be either motivated by internal or external factors. According to the third theory, social-cognition, change can also happen because of people reaching a cognitive dissonance when values and actions clash or something becomes passé then they change and start learning new approaches, making sense of phenomena by viewing the organisation through different lenses and by reframing issues. Organisations fail because of lack of comprehension of the change at hand. While in the fourth theory, cultural, change occurs because cultures are not static they evolve. Change in this theory includes modifications in values, beliefs, myths and rituals (Schein, 1985).

In addition to exploring issues surrounding the organizational change theories it is also necessary to consider the determinants of organizational change. One of the determinants is a shift in the organisational behaviour of schools from a silo mentality to that of engaging communities through modification of factors that might be allowing or sustaining silo beliefs and behaviors. Chisita and Abdullahi (2012 p. 2) argue that silo mentality is an organisational approach that views situations from a narrow minded perspective rather than holistic perspective. The consequences of having a silo mentality relate to four main factors: barricading access to resources; lack effective management of creativity and innovation (Stone, 2004 p.12); substantial failure to achieve goals; and likelihood of duplication of services (Chisita \& Abdullahi, 2012 p. 2). Implications of resistance to change are therefore complex in terms of effect to health promotion efforts.

Another determining factor according to Weiner (2009), is readiness of organisations to change which implies a state of being psychologically and behaviourally ready to take action. Readiness can translate to commitment to the change process, time to consider capacity to perform the task at hand (Gist \& Mitchell, 1992 p. 184), an organisational culture that embrace innovation and risk-taking (Jones, Jimmieson \& Griffiths, 2005) and to smoother adaptation to change. In contrast, organisations that are not ready for change will be reactive in their approach as a result lack direction and a clear sense of purpose.

Clear goals according to Rhydderch, Elwyn, Marshall and Grol (2004 p. 214), determine proactivity and smooth adaptation to change as the understanding of these goals is part of sense making processes. Where goals differ conflict is inevitable, therefore activities need to be aligned to the developed goals to achieve results. In addition, Dakers (2003 p.47) notes that clear objectives and a commitment to fulfill such objectives can lead to successful partnership between schools and their communities. The author further suggests that demarcating the responsibilities of those involved, effective communication and persistence in pursuing goals can eliminate conflict and accelerate performance.

\section{School Community Participation}

Since the 1960s community participation has been a preoccupation in research. Schools do not exist in isolation of the communities in which they operate (Barton \& Drake, 2002) and it has long been recognized that schools are more likely to be effective through cooperation with parents. The school community is composed of parents of learners in the school, members of business community, the Non-Governmental organisations, a network of agencies, the church community and government departments. It is people from these communities that have a potential to support and sustain a protective, healthy school environment. It is true that effective school change involves learners and their families (Marx, 
Wooley \& Northrop, 1998 p. 11) for the operational success and local credibility of health promotion (Denman et al. 2002 p. 35). Schools provide services to their communities and although not often acknowledged, they need advice and support of these communities in order to effectively respond to their aspirations and needs. There is therefore a need for real participation as opposed to token participation. Thus, school community participation is one of the propagations of conceptual frameworks that help to guide the movement of health promotion from theory to practice. It is therefore important for schools to understand school community participation, its importance and execution.

\subsection{Levels of participation}

Both Arnstein's (1969) ladder of participation and Pretty's (1995) typology of participation guide the discussion in this section. It was necessary to employ both theories as the former speaks to communities at the receiving end while the latter speaks to the user of participatory approaches (Cornwall, 2008 p.70). Guthrie and Schuermann (2010 p. 361) argue that although schools typically have the luxury of being surrounded by abundance of community partners as mentioned earlier, not all community members are compatible with schools. Community members who do not see eye to eye with the school will be reluctant to participate in the school's activities. According to Arnstein (1969) the level of nonparticipation is the lowest in the ladder of participation. Therapy and manipulation are placed at this level. Such a level can compose of occasional volunteering activities in food gardening projects and cleaning of classrooms by parents as examples. A narrow preoccupation with volunteering provides neither community members genuine full participation nor an opportunity to be part of decision making. Restrepo (2000) warns against coercive or manipulative community participation as such tendency according to Arnstein (1969) would put community members at the receiving end of health projects and programmes.

The next level is that of tokenism which includes consultation, informing and placation. Schools in South Africa are mandated to develop school-based health policies if not possible schools can make use of national policies. The development of school-based policies is to demonstrate their commitment in addressing health issues pertaining to their environments. It is recommended that policy development be inclusive of all stakeholders in order to gain cooperation and buy in of community members. It is common for schools to develop these policies and then communicate them in parents meetings. The real objective in such an action is not to allow for participation in decision making or for parents to make a contribution but to just inform whilst the decision is taken by the school on what is regarded as important. In such instances schools still perpetuate school-focused approaches that only serve school determined interests (Mitchell, 2008 p. 4). According to Cornwal (2008 p. 270), the intention of such parent gatherings are to legitimise what has already been decided to give it a moral authority. Under such conditions community participation is disregarded by the school thereby refuting healthy aspects of community participation. The Policy Brief (2009) warns against 'one-size-fits-all' where health programmes are implemented without taking into consideration the local context including cultural mechanisms or social practices validated by the community.

When participation is restricted only to the levels discussed above, both the community and the school are at a loss as there is no assurance or commitment to the implementation of strategies. These bad forms of participation indicated as manipulative and passive need to be fully eliminated as they become hindrances to achievements of goals in a school.

The highest level, the citizen power includes control, delegated power and partnership. Nichols-Solomon (2000 p. 20) indicates that an intense community involvement means shared leadership which is related to sharing knowledge, responsibility, and most difficult of all, power. Communities make their own decision on either being involved or not based on their perception of how open the school is to their participation (Henderson \& Mapp, 2002) and the level of trust in the school which in turn determines their level of participation. When communities trust the school, its activities can be regarded legitimate, the opposite then leads to the loss of such legitimacy. Full participation according to NEE (2004 p. 80) offers an opportunity for identification of community-specific health issues and strategies that can be employed in health promotion in schools by so doing breaking the divide between schools and their communities. A school's success can be attributed to a high degree of community participation in the health promotion objectives and processes because of the responsibility that is shared by all. The California Department of Education (2003 p. 193) highlights the vitality of community participation in supporting and strengthening the schools' activities, thereby, enhancing the effectiveness of programmes by stimulating awareness about health (Perez-Rodrigo \& Aranceta, 2001). Full participation can also translate into a synergy between school communities, government departments and schools. Raeburn, Akerman, Chuengsatiansup, Mejia and Oladepo (2007 p. 86) argue that synergy is the pillar of health promotion initiatives. 


\subsection{Challenges in engaging communities in SHP}

Reasons for non-community participation are dealt with extensively in research in general, Mitchell (2008 p. 2) elaborates on factors ranging from logistical issues to factors associated with the school culture and as discussed in the foregoing paragraphs how welcoming the school is to parents. Besides these contests, it can be a challenge to convince community members to support school health programmes and also provide contributions of kindness. This is so because community members nowadays are used to receiving payments or stipends from NGOs and schools for similar services. The volunteer food handlers who are part of the National School Nutrition Programme (NSNP) responsible for preparing meals for learners are paid a stipend every month. These volunteer food handlers sign a year contract with schools which is not renewable. A study conducted by Rendall-Mkosi, Wenhold and Sibanda (2013) in 12 schools, in the Eastern Cape and Mpumalanga provinces in South Africa found that there was very little community participation in the meal provision or school garden projects beyond a few parents being involved in the NSNP committee. Community volunteers who are invited to participate in school gardening projects do not get a stipend and their lack of participation can be attributed to this.

In both health programmes mentioned in the foregoing paragraphs community members are invited by the school, invited participants have according to Cornwall (2008 p. 281) an opportunity to secure resources. "Invited participation" is autonomous and a part of the definition of participation in practice. In school garden projects volunteer participants have a voice, deciding on the crops to be planted, when to plant, when to reap and what to do with the harvest which they usually share with NSNP. Volunteer food handlers do not enjoy the same autonomy, although their participation is part of development as volunteers in food gardens, they are not coequals in decision making.

The delegation of power is another challenge that schools are struggling with in allowing communities to participate in their activities. The difficulty is in empowering school communities to have a direct interaction with the school in shared decision making and setting of goals (Sands, Kozleski \& French, 2000). The first step is to move from traditional perception of "power over" communities which is autocratic to power with and through communities (Cranston, 2001 p. 4) indicating a democratic approach. It is in this very step that schools seem to be stuck, unable to share their vision and communicate clearly benefits of their activities to their communities thereby ensuring that communities buy into the school's idea. The development of health policies and communicating them to parents for their approval is evidence of this inability to share power which in turn can perpetuate non-participation. Full participation by all community members would be practically impossible and time-consuming. The way forward would be to strike a balance between full participation which engages participants in all stages of policy development and implementation (Farrington \& Bebbington, 1993) and inclusion of those who represent the wider community such as the School Governing Body Members and other bodies that represent the community in a school.

Sex education which is one of the health promotion programmes according to UNESCO (2008) is value based. Schools have to understand the values their communities uphold in order to implement their interventions effectively. A clash in values triggers resistance. In a study conducted by Ahmed et al (2009 p.51) educators remarked about their added responsibility of instilling values and morals into learners which are not taught at their homes. A plethora of researchers both nationally (Goldman, 2008; Mukoma, Flisher, Ahmed, Jansen, Mathews \& Klepp, 2009) and internationally (Poobalan et al. 2009) alluded to parent resistance to sexual health education at schools including programs providing information about contraceptive options.

In summary, it is thus clear that the school's (1) representation of the community's aspirations for the future; (2) ability to effectively recruit and partner; and (3) having strategies in place to sustain community participation are instrumental in the success of community participation.

\section{Methodology}

A qualitative research method using a multiple case study design was used to generate information from two areas in one province in South Africa. The topic of interest in this research was to determine challenges and opportunities regarding community participation in health promotion in schools. Data was generated by means of individual interviews with participants from schools in Embalenhle and Standerton in the Gert Sibande District in Mpumalanga Province. Four schools: two primary and two high schools participated in this research. Both Embalenhle and Sakhile townships are poor areas with a high rate of unemployment and HIV prevalence. Schools that participated in this research were targeted because of their participation in the Eco schools programme. This information was revealed by a key informer an official in the Gert Sibande District responsible for many of the primary and secondary schools in these townships. As Pojjie (1972) suggests the key informant was selected for his knowledge and role in schools in the Gert Sibande district. Twelve 
school personnel participated $(n=12)$ four principals one from each participating school $(n=4)$ and two chairpersons of health committees in each school $(n=8)$.

\title{
5. Data Analysis
}

\subsection{Lack of participation in decision making}

In all four schools parents were not part of health policy development at Embalenhle, policies were developed by school committee members then communicated to parents in parents meetings. All four schools had developed school-based policies.

\begin{abstract}
"We sat down as a committee drafted the policy, sent it to the principal who made parents aware of it in a parents meeting" (P2C); "We develop our policies as a committee everyone else is involved later when the policy has been finalised" (P1D); "We will never have a policy if we can include parents, they don't know what we do" (P3A); "we involve them in the end it's not that we don't involve them at all we consult'( $(P 2 B)$; "They don't know anything about development of policies" (P1C); "We have never approached them on policy development, we have always done this this way"(P2A).
\end{abstract}

However parents were invited in celebrations, all participating schools had celebrations once or twice in a year in acknowledgement of their achievements in participating in health programmes run by companies or NGOs. Most parents had no problem attending these celebrations, although the aim of schools was just to show them that they were doing something, therefore legitimize the activity.

\begin{abstract}
"All parents are invited when we are celebrating our awards" (P2C); "We are told by the company or NGO to invite parents, it also gives us an opportunity to show off to them" (P3D); "We also enjoy this time everything comes alive, everyone excited about the event, SASOL or WESSA also gives educators who were part of the programme a certificate or award" (P3B); "Parents are not part of the organizations of celebrations we include one member of the SGB in the programme to thank the organisers on behalf of the school" (P2A).
\end{abstract}

\subsection{Community participation in the implementation of health programmes}

The participating schools established the following committees to implement their strategies: Environment, Sports, Feeding Scheme; HIVIAIDS (or Health, in other schools both exist). Two programmes, the environment awareness and feeding scheme were implemented effectively at least better than the rest, the former is run by WESSA and the latter by the Department of Education in collaboration with the Department of Health. Reasons for this disparity were indicated as follows:

"We receive training from WESSA or SASOL" $(P 2 D)$; "There are people who come and check if everything is fine regarding nutrition"(P1C); "It is better we know exactly what we have to do, we get guidance in the training" (P2A); "Monitoring, I like the fact that they are part of this, we don't have to do everything" (P2B); "You don't struggle alone, we can phone and ask (P3D).

Although the NSNP does not rely entirely on the community contributions it needs the support in order to be sustainable and reach as many learners as can be. Garden projects had been linked to this programme since it started in 2002. Community members had always been at the forefront of implementing this programme with an aim of supplementing the food that learners get from school as per policy. Participants had conflicting views on the involvement of the community in this programme.

"Parents participate in the garden project as volunteer, it is up to them, we cannot force them to participate" (P1A); "Gardening is a community project and therefore does not benefit the school" (P1D); "From their produce they must contribute something to the school for the feeding scheme, sometimes they do but most of the time they take the food for themselves" (P2B); "It is the school that helps them to get assistance from the Department of Agriculture, last year they got a green house" (P2A); "I cannot even remember it has been some time since we had vegetables from the garden" (P1C); "Most of the time they get a lot of produce like last year, the school did not benefit" (P1A).

Another area where community participation is visible is in cleaning and NSNP at schools. In both these programmes unemployed parents are recruited by the school to voluntarily participate in such programmes. Community members are paid a stipend for their service. 
"Parents work as food handlers for a year then they are replaced by others who are not employed"(P3A); "We don't struggle to get them, there are a lot of them waiting to be part of the programme" $(P 2 B)$; "They prefer to be cleaners rather than food handlers, in cleaning they are permanent" (P3C); "They are allowed to resign from being members of the SGB if they want to be part of the NSNP or cleaning" (P3B).

\subsection{Community projects at schools}

Schools A and B were part of two projects run by a company and an NGO. The first, the Green Cage and Eco Schools' project sponsored by SASOL which started in 2008 with an intention to keep the environment clean by means of recycling. The second project was that of Wildlife and Environmental Society of South Africa (WESSA).

"Two educators were trained to develop a portfolio of evidence indicating activities which the school undertook to incorporate the project into their teaching (P1A); 'We are to prepare environmental friendly lesson plans, where they would teach about the environment whilst addressing their content in class' $(P 2 A)$. 'The portfolio is assessed by WESSA, and an official from the Department of Education $(P 1 A)$; "The highest medal the school got was bronze, and then certificates of participation in cleaning campaigns in 2004 and 2005' (P1B).

In school B a Non Governmental Organisation (Manna for TEKS) and an NGO, Soul City which is a national intervention programme and prominent members of the community were involved in some health programmes.

"Members of the local community assist with sport attire, equipment for sport, and uniform, while TEKS helps us with food for learners" (P1B). "We received trees, seeds and flowers from the local municipality" $(P 2 B)$; "Soul buddies are trained by people from Soul City, they identify learners that are struggling and report to educators and the principal"; "The Soul City helps, a lot, we cannot be able to identify learners that are struggling with food, uniform, sick etc without their assistance, they do a good job"

Participants indicated motivators to being part of community projects. The top of this list is the awards or rewards and training provided by companies and NGO's.

"The school achieved immensely by attaining bronze in 2009 and silver in 2010" (P1A). This school qualified for an Eco Green Flag in 2011, which meant that we were internationally recognized as participating in the programme (P2A); 'During training teachers were taken on a tour to Pretoria to visit a place specializing in environmental issues' $(P 2 B)$

\subsection{Taking initiative to engage communities}

It seems that the staff members are able to ask for help from their communities when the need arise and the organizations are able to come and offer help. The problem is that the engagement of communities is to satisfy a special need and it never goes further than that.

"We go out to ask for resources from the NGOs and companies"(P1D). "We asked the nurses to train us on first aid"(P1A); "We ask for donations from the community when we are fund raising"(P3C); "We usually send members of the committee to ask municipality for trees in spring" $(P 2 B)$; "We need the communities although it is difficult sometimes to approach them it pays off at the end" (P3A).

Participating schools struggle to form lasting relationships with their communities indicating lack of a clear strategy to engage communities, ineffective leadership and lack of willingness among staff members.

"We are not sure where to start" (P2B); "It would be a wonderful idea if we can have an NGO that is committed to assist us, but I don't know how we can do this, maybe they are also busy" (P3C); "Usually the community members approach us if they want to be part of the school activities, it is not the other way round except when we ask for donations" (P1D); "It could help but we have our committee meetings during the day when some of them are at work" (P3A); "I am not sure about this some will not understand what we intend to do and maybe we will spend a lot of time explaining" (P2D); "It works with the SGB because members are trained but with health educators need the training how much more with parents?" (P1B).

\subsection{Challenges in the implementation of health programmes}

The attitude of educators towards the implementation of health programme is apparent in the following statements. 
"They don't want to do them because it is not part of their job description"(P1C); "Some trainings are conducted in the afternoon until late so educators don't like to work until very late"(P2D); "Yes I was trained, it was just a 3 day course five years ago, I need a refresher course (P1A); No one is responsible for the first aid kit, the clerk keeps it in the office, no one checks whether the contents expired or not" (P2C); "They get tired of being too much involved in these programmes, it hinders their progress in class" (P3B); "We have to cover the syllabus" (P3D); "We have to cover the syllabus" (P3A).

The lack of training of teachers by the Department contributed to the failure of some programmes. The availability of a fully equipped first aid kit and its use is a requirement in the National Policy on HIVIAIDS (Act 84 of 1996) as a means to precautionary measures. Schools are not only expected to have these kits accessible during teaching time but also during sporting events and school outings. Schools have over the years been trying to meet this requirement with

"We know nothing about first aid, no one was trained here" (P1D); "We just do our best, no one knows anything about first aid" (P2C); "Parents don't trust us, I don't blame them, others told us to just send their children to the clinic" (P1A); "

Schools indicated that their committees were not functional it was therefore difficult for them to meet their targets at the end of each year. There were no strategies in place to deal with this in fact it was as if the school was lucky if at least there was one educator in the committee who was willing to do the work on behalf of all the other members..

"We are struggling with committees, every year there are educators who no longer want to be part of this or that committee" (P1C); 'Others do not say anything but you find that they are not active or they do not care about the duties of the committee" (P2A); 'sometimes the principal talks to them, tries to motivate them but there is nothing he can do also" (P3D).

\section{Discussion}

The limitation of this research is due to the characteristics of its sample. Two parties that are involved in this research are schools and their communities. Data in this research was generated only from participants from schools therefore, the results are based on the perceptions of school personnel and not of their communities. Lack of focus on communities especially those that took the initiative of creating spaces to participate in school health promotion highlight the need for further exploration of this issue.

The finding in this research is that schools do not create much space for communities to participate, even where this is a statutory obligation as the ISHP (2012), White Paper 6 (1996), National School Nutrition Programme (1996) and the Department of Basic Education Integrated Strategy on HIV, STIs, and TB 2012-2016 (2012) all emphasise the importance of community participation. Communities are not part of decision making in health promotion even if they are members of the School Governing Bodies (SGB), their participation is limited to instances where they are informed about decisions taken and consulted about health policies and where they are expected to just endorse the decisions thus rendering shallow participation in just few selected areas.

Using Pretty's (1995) typology of participation this amounts to passive participation which according to participants in this research is justified by their lack of trust in community members. The level of community participation is thus determined by this lack of trust. Gold, Hartmann and Lewis, (2005) and Henderson and Mapp (2002) emphasise the importance of establishing caring and trusting relationships between communities and schools. Furthermore, for the same reason health programmes are not clearly communicated to communities to allow them to determine their own role thus communities continuing to be passive recipients. As a result more often communities reject some health programmes. For an example the schools' Voluntary Counselling and Testing campaign has been struggling to take off since its launch in 2010 mainly due to lack of consent from parents and lack of confidentiality. This highlights conflicting values between health programmes and communities.

The second finding is that where communities took the initiative to create spaces themselves for participation in health programmes in schools there was no resistance from the participating schools. What can be learnt from these initiatives is that community organisations create a shared sense of ownership around health promotion from the start and retain a focus on activities, interventions and incentives to encourage school participation and avoid participation fatigue. Unlike in schools' initiatives community organisations' programmes were not only better organized but educators were trained, resources provided and the health programmes monitored. The greatest motivator for educators was the awards and the ceremonies which they shared with the community. The participating schools failed to make use of this opportunity to build lasting relationships with the community organisations and to garner their support for the programmes they struggle with. Projects from the community have a history of not being there forever, reason being that community 
organisations had specific goals they want to achieve and certain targets to meet, when these targets are met they no longer continue with them. NGOs loose funding and it becomes difficult for them to continue, but organisations such as WESSA and the Soul City have expertise and capacity to assist schools in training educators and providing resources within their scope of operation.

The third finding is that educators had a negative attitude and lack of commitment towards health programmes that they had to implement on their own. The reason could be that unlike community projects there was no support from the department and no incentives. Skinner (2001) argues that it takes time, adequate support and guidance for organizational behavior to change. Educators have always been at the forefront in the implementation of health programmes because they make contact with learners on a daily basis and are familiar with some concepts of health promotion. It has always been difficult for educators to embrace a concept that involves extra work. Perhaps this is the reason why the Department of Basic Education embarked on competitions between schools on the NSNP to motivate schools

Each of these findings offers an opportunity for schools to implement change in their approach to community participation. The first and the last findings can be internal triggers for change. The need for paradigm shifting is evident in the attitude of schools towards their communities as their resistance to change by opening spaces for communities is tied to their belief that they are educators, it is their responsibility to implement health programmes. This silo mentality which has become an organizational culture continues even when community organisations are part of these schools. According to Cameron (1991) having ceremonies and events that alter culture can create change. It is only when these schools make retrospection of what they do and their beliefs that their world views can be shaped and altered. Thus change activities should focus on altering these beliefs.

\section{References}

Chisita, CT. \& Abdullahi, I. (2012). Rising above the grain silo mentality through collaboration: Creating opportunities between the LIS educators and practitioners in developing countries. Proceedings of the $78^{\text {th }}$ IFLA general conference and assembly, Web: http://conference.ifla.org/ifla78 Date of access: 09/07/2014.

Cranston, NC. (2001). Collaborative decision-making and school-based management: challenges, rhetoric and reality. Journal of Educational Enquiry, 2( 2): 1-24.

Dakers, H. (2003). The BL Reaches out. IN: Library and Information Update, 2(10)

Francis, DA. (2011). Sexuality education in South Africa: Wedged within a triad of contradictory values. Journal of Psychology in Africa, 21(2): 319-324.

Gold, E., Hartmann, T. A., \& Lewis, K. S. (2005). Children and Families First: An Evaluation of the Philadelphia Say Yes to Education Program. Philadelphia: Research for Action.

Gist, ME. \& Mitchell, TR. (1992). Self efficacy - a theoretical analysis of its determinants and malleability. Academy of management review, 17: 182-211.

Goldman, J. D. G. (2008). Responding to parental objections to school sexuality education: A selection of 12 objections. Sex Education, 8 (4): 415-438.

Henderson, A.T. \& Mapp, K.L. (2002). A new wave of evidence: The impact on school, family, and community connections on student achievement. Southwest Educational Development Laboratory: Austin, TX.

Hinde, E. (2003). Reflections on reform: a former teacher looks at school change and the factors that shape it. Teachers' college record. Web: http://www.tcrecord.org. Date of access- 07 May 2014.

Jones, RA., Jimmieson, NL. \& Griffiths, A. (2005). The impact of organisational culture and reshaping capabilities on change implementation success: the mediating role of readiness for change. Journal of management studies, 42: 361-386.

Kezar, AJ. (2001). Understanding and Facilitating Organizational Change in the 21st Century: Recent Research and Conceptualizations: ASHE-ERIC Higher Education Report, 28:4. San Francisco: Jossey-Bass.

Mitchell, C. (2008). Parent Involvement in Public Education: A Literature Review. Web: www.researchforaction.org. Date of access- 07 May 2014.

Mukoma, W., Flisher, A., Ahmed, N., Jansen, S., Mathews, C. \& Klepp, K. (2009). Process evaluation of a school-based HIVIAIDS intervention in South Africa.

Scandanavian Journal of Public Health, 37: 37-47.

Nichols - Solomon, R. (2000). Conquering the fear of flying. Phi Delta Kappan.

Poggie J. (1972). Toward quality control in key informant interview data. Human Organization, 31:23-32.

Policy Brief (2009). Promoting participation: Community contributions to education in conflict situations. Web: www.iiep.unesco.org. Date of access- 07 May 2014.

Poobalan, A. S., Pitchforth, E., Imamura, M., Tucker, J. S., Philip, K., Spratt, J., \& Van Teijlingen, E. (2009). Characteristics of effective interventions in improving young people's sexual health: A review of reviews. Sex Education, 9, 319-336.

Pretty, J. (1995). Participatory learning for sustainable agriculture. World development, 23(8): 1247-1263.

Raeburn, J. Akerman, M. Chuengsatiansup, K. Mejia, F. \& Oladepo, O. (2007). Community capacity building and health promotion in globalised world. Health promotion international, 21(S1): 84-90. 
Rendall-Mkosi K., Wenhold F. \& Sibanda, NB. (2013). Case Study of the National School Nutrition Programme in South Africa . Pretoria: $P C D, N E P A D$ and DOBE

Rhydderch, M. Elwyn, G. Marshall, M. \& Grol, R. (2004). Organisational matters: organisational change theory and the use of indicators in general practice. Quality Saf Health Care, 13:213-217.

Sanders, D. Bradshaw, D \& Ngongo, N. (2010). The status of child health in South Africa. (In: Kibel M, Lake L, Pendlebury S \& Smith C (eds) South African Child Gauge 2009/2010.)

Sands, DJ., Kozleski, EB. \& French, NR. (2000). Inclusive education for the $21^{\text {st }}$ century. Belmont: Wadsworth.

Stone, F. (2004). Deconstructing silos and supporting collaboration. Employment Relations Today, 31(1)

Weiner, BJ. (2009). Debate: a theory of organizational readiness for change. Implementation Science, 4:67. 